\title{
Role of microsimulation in evaluating intelligent transportation systems applications in urban transportation
}

\author{
A. M. Khan ${ }^{1}$, J. Armstrong ${ }^{2}$ \& A. Munir ${ }^{3}$ \\ ${ }^{1}$ Carleton University, Ottawa, Canada \\ ${ }^{2}$ Morrison Hershfield Limited \& Carleton University, Ottawa, Canada \\ ${ }^{3}$ Morrison Hershfield Limited, Burlington, Canada
}

\begin{abstract}
Given the complexity and novel aspects of ITS-based measures for transportation network improvements, traditional macroscopic travel analysis models are of limited utility for assessing project benefits and costs. To fully capture the operational-level impacts of such technologies, a microsimulation approach is required. This paper describes the use of microsimulation techniques for studying the relative effectiveness of alternatives that include ITS applications. To illustrate the methodology, a case study involving the transportation network in Ottawa, Canada is presented. The paper is divided into five parts. First, mobility issues and the need for innovative solutions are introduced. Second, the transportation network in Ottawa is described and potential initiatives for addressing traffic congestion are noted, including demand reduction, freeway capacity expansion, and selected ITS measures. Third, the microsimulation-based modelling methodology is defined which was used to test improvement scenarios. Results from the various micro-simulation runs are then presented in terms of selected measures-of-effectiveness. Finally, conclusions drawn from the case study are presented.
\end{abstract}

Keywords: urban transportation, intelligent transportation systems, microsimulation, freeway-arterial integrated network, transportation management, evaluation. 


\section{Mobility issues}

Sustainable transportation requires a commitment to meeting mobility needs in an equitable and efficient manner while minimizing environmental impacts. If efforts to develop a sustainable transportation system are to be effective, it is important to investigate ways to minimize infrastructure expansion while maintaining an acceptable level of service to drivers. To meet urban travel needs and avoid unacceptable traffic congestion, a balance of travel demand management, traffic management, and strategic road network improvements is required. Physical capacity enhancement has a role to play in meeting mobility needs, but there are limits to infrastructure expansion owing to lack of space, excessive cost and the phenomenon of induced traffic.

At the present level of technological development, it is possible to increase the productivity and efficiency of the transportation network through the use of Intelligent Transportation Systems (ITS) as a substitute for infrastructure expansion or as a supplemental measure. Indeed, Intelligent Transportation Systems (ITS) have reached a stage in their development path where they can now be effectively used to increase efficiency, enhance safety, and also reduce energy consumption and emissions in urban transportation [1]. A number of definitions of ITS have been advanced (for example, see Transport Canada [2]). In general, ITSs are comprised of four key elements: the vehicle, the infrastructure, the communication system, and the user. Figure 1 illustrates these elements, and their interaction with each other.

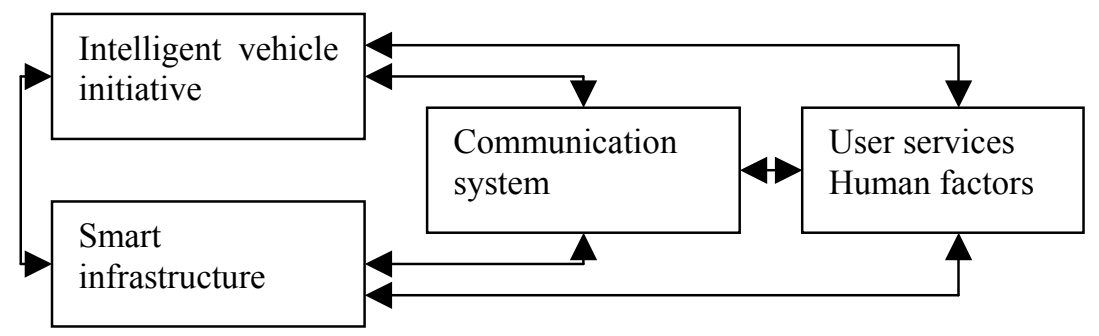

Figure 1: Components of Intelligent Transportation Systems.

This paper describes the use of microsimulation techniques for studying the relative effectiveness of network improvement measures that include ITS applications.

\section{Network and improvement scenarios}

A case study was conducted for the Highway 417 corridor in Ottawa, Canada. Highway 417 is an east-west freeway which serves as a major transportation corridor through Canada's National Capital Region. Although peak period congestion and its effects are experienced throughout the Ottawa freeway and arterial network, the Highway 417 corridor in particular is impacted by a 
substantial imbalance between automobile travel demand and available capacity (Figure 2).

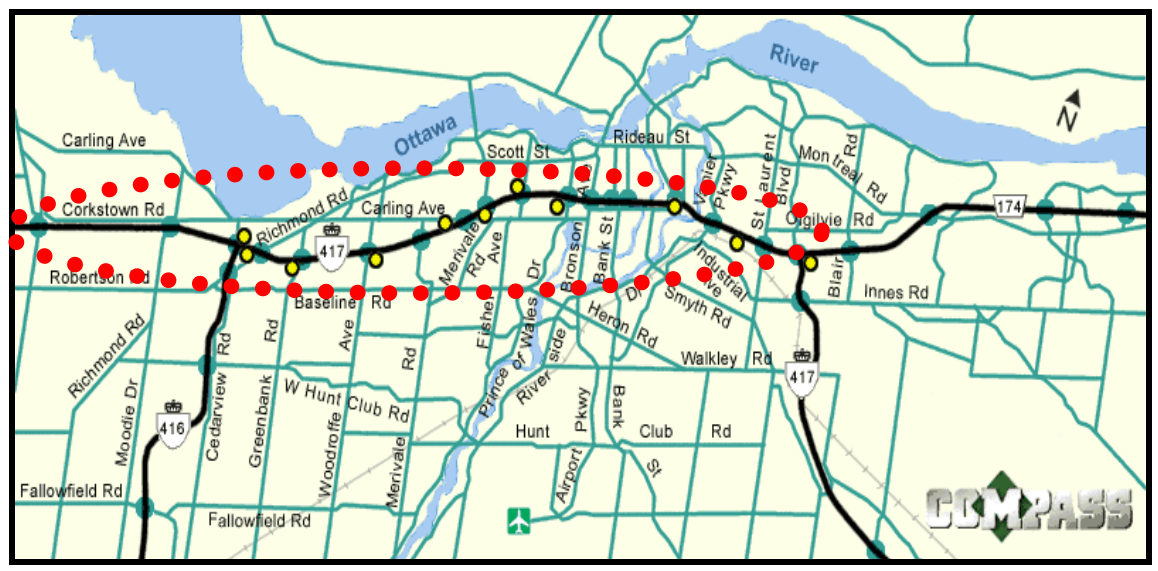

Figure 2: Ottawa freeway and arterial network (Courtesy of the Ontario Ministry of Transportation Website).

Three categories of improvement measures were identified to address the traffic congestion currently experienced on Highway 417 (Figure 3). The first category is targeted at achieving a $20 \%$ reduction in automobile travel demand in the corridor. This could be achieved by such demand management measures as modal shift to public transit, telecommuting, flexible work hours, and ITS-based congestion pricing. These measures have been effective in a number of urban areas around the world and it is therefore expected that such measures could potentially reduce peak period demand in the study area.

The second category of improvement initiatives calls for adding road capacity to the Highway 417 corridor through the provision of additional lanes. The third category involves a package of ITS-based operational-level initiatives, including ramp metering, incident management, variable message signs, and traveller information/navigation.

While the overall focus of the research has been on the ability of each improvement measure to enhance traffic operations on Highway 417, different sections of the highway were selected for analyzing different options. The section of Highway 417 between the interchanges of Richmond Road in the west and St. Laurent Blvd. in the east was used for research on ramp metering. The integrated freeway-arterial network west of the Highway 416 interchange was used for investigations on demand reduction, lane expansion, and a number of ITS-based initiatives for traffic management. This part of the City of Ottawa includes the communities of Kanata and Bells Corner's, as well as a portion of the greenbelt which separates the west urban community from the central part of the city. This area has undergone rapid development in recent years, resulting in traffic congestion on the main routes. 


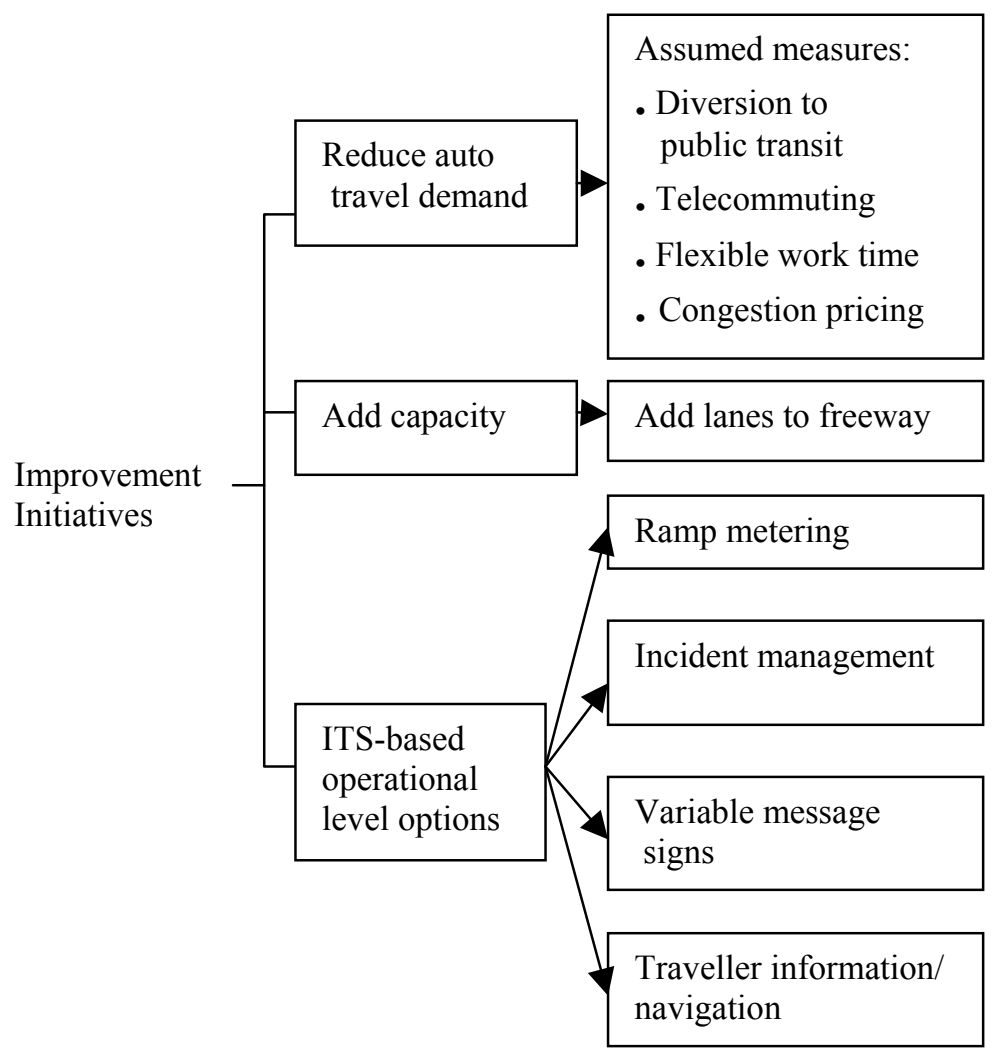

Figure 3: $\quad$ Selected improvement initiatives.

\section{Methodology}

For a detailed analysis of traffic flow improvement options that include ITS technologies, coarse macro-level planning tools are of little use because they do not capture interaction between individual vehicles. In contrast, the microscopic approach facilitates the analysis of many dynamic traffic phenomena, such as shock waves, gap acceptance, and weaving, which are often difficult to capture under non-steady state conditions using macroscopic planning and analysis tools [3]. Figure 4 presents the main components of a microsimulator [4]. Given their ability to model the car-following, lane-changing and route choice decisions of drivers, microsimulators are well-suited for the analysis of ITS-based improvement options [5].

To assess the effectiveness of ramp metering, a model was developed using the microsimulation software, CORSIM. CORSIM is part of the Traffic Software Integrated System (TSIS) developed by ITT Systems and Sciences Corporation under the direction of the U.S. Federal Highway Administration [6]. This software package offers a variety of metering options and tracks the movement 
of all vehicles on a second-by-second basis. In carrying out the assessment, traffic conditions in the study area were modelled for both the morning and afternoon peak hour of travel demand using a base year of 2001 .

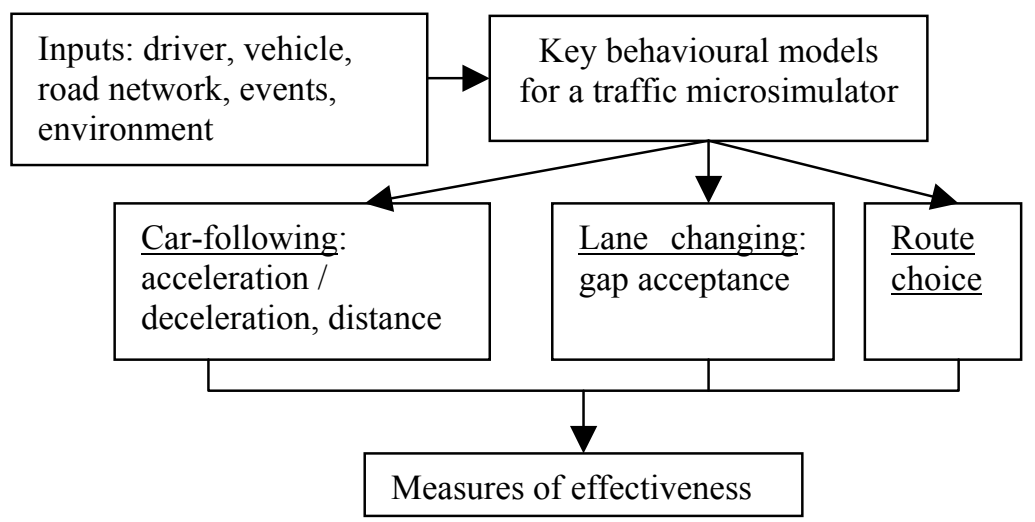

Figure 4: Major components of a microsimulator. (Source: [4].)

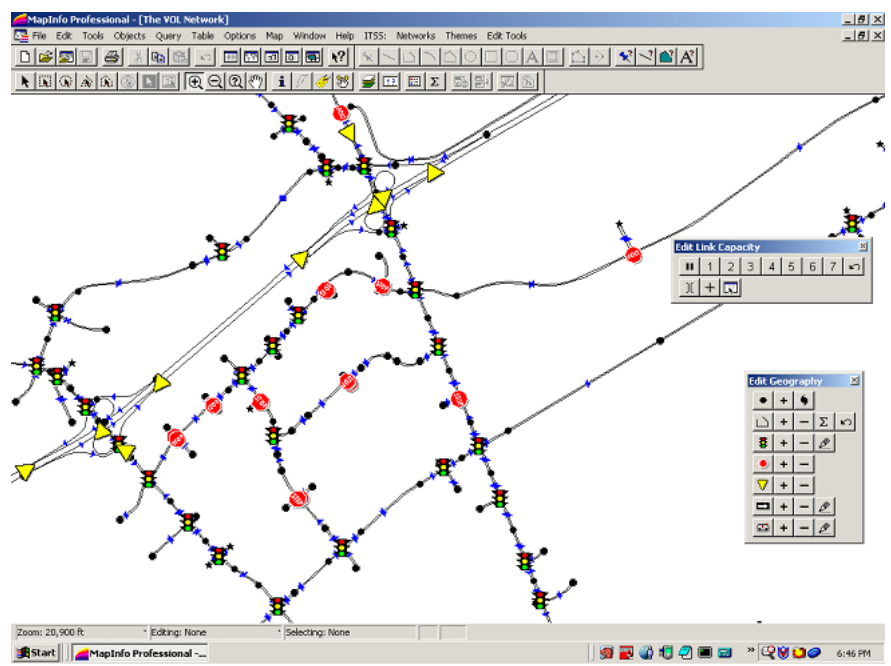

Figure 5: $\quad$ MapInfo editing environment.

For testing improvement options in the integrated arterial/freeway network, the microsimulator INTEGRATION was used in conjunction with the GIS software, MapInfo. INTEGRATION is a microscopic traffic simulation model that is capable of tracking the movement of each vehicle on the road network at a resolution of one deci-second [3]. 
To simulate traffic operations in INTEGRATION, files related to network characteristics and travel demand were created. The travel demand inputs were developed using QueensOD, a software package available from the developers of INTEGRATION. This software uses a synthetic O-D estimation procedure to develop trip tables based on observed link flows [7]. For the integrated network model, the travel demand corresponds to the afternoon peak hour in the year 2000.

In order to prepare the various inputs required for microsimulation at a network level, the use of GIS and related software is highly desirable. Accordingly, the network files for INTEGRATION (and QueensOD) were developed using MapInfo. To assist in the development of the INTEGRATION network, a MapInfo application called the INTEGRATION Traffic Simulation Shell (ITSS), developed by the City of Portland's Office of Transportation, was used. Figure 5 provides a snapshot of the MapInfo editing environment.

\section{Scenarios and results}

For each of the improvement initiatives described in Section 2, measures-ofeffectiveness (MOEs) were produced using the microsimuation approaches described in Section 3. Due to space constraints, only the MOEs for delay per trip and fuel consumption per trip are reported in this paper (refer to Tables 1 to 6). Delay is found by calculating the difference in travel time between travel at a vehicle's instantaneous speed and free-flow speed.

The results in Table 1 correspond to the scenario in which peak period vehicle demand was reduced by $20 \%$ over the integrated arterial/freeway network. As expected, demand reduction is highly effective in improving traffic flow on a network basis and consequently reducing average delay. Fuel efficiency also improves as a result of reduced demand.

Table 1: $\quad$ Effectiveness of reduced demand.

\begin{tabular}{|l|c|c|}
\hline \multicolumn{1}{|c|}{ Measure of effectiveness } & Base case & Reduced demand \\
\hline Average delay (min/vehicle) & 10.4 & 5.3 \\
$\%$ change & - & $-49.0 \%$ \\
\hline Fuel consumption (litres/trip) & 1.11 & 0.95 \\
$\%$ change & - & $-14.4 \%$ \\
\hline
\end{tabular}

Table 2: $\quad$ Effectiveness of new capacity.

\begin{tabular}{|l|c|c|}
\hline \multicolumn{1}{|c|}{ Measure of effectiveness } & Base case & New capacity \\
\hline Average delay (min/vehicle) & 10.4 & 9.4 \\
$\%$ change & - & $-9.6 \%$ \\
\hline Fuel consumption (litres/trip) & 1.11 & 1.08 \\
$\%$ change & - & $-2.7 \%$ \\
\hline
\end{tabular}


In the capacity expansion scenario, Highway 417 was widened from a fourlane cross-section to a six-lane cross-section in the study area. This scenario provided an opportunity to assess the relative merit of ITS initiatives compared to traditional capacity-building projects. The results presented in Table 2 are favourable but not as dramatic as in the case of demand reduction.

Ramp metering was tested on Highway 417 between Richmond Road and St. Laurent Boulevard, a section of highway encompassing a total of 16 interchanges. Eight locations were metered where demand currently exceeds capacity. These locations were selected following a study of historical data trends for peak period travel in each direction. The ramp metering assessment focussed exclusively on Highway 417; the effect of ramp metering on the adjacent arterial network was not considered. As shown in Table 3, the impact of ramp metering is highly favourable in terms of freeway operations.

Table 3: $\quad$ Effectiveness of ramp metering (freeway traffic only).

\begin{tabular}{|l|c|c|c|}
\hline \multicolumn{1}{|c|}{ Measure of effectiveness } & $\begin{array}{c}\text { Base case } \\
\text { (no metering) }\end{array}$ & $\begin{array}{c}\text { Clock time } \\
\text { metering }\end{array}$ & $\begin{array}{c}\text { Demand- } \\
\text { capacity } \\
\text { metering }\end{array}$ \\
\hline $\begin{array}{l}\text { Average delay (min/vehicle) } \\
\text { \% change }\end{array}$ & 30.6 & 26.9 & 12.0 \\
\hline $\begin{array}{l}\text { Fuel consumption (litres/trip) } \\
\text { \% change }\end{array}$ & -2.13 & $-12.1 \%$ & $-60.8 \%$ \\
\hline
\end{tabular}

To study the effects of incident management, a scenario was developed in which a collision on Highway 417 (between Eagleson Road and Moodie Drive) resulted in the closure of one full lane of traffic in the westbound direction for a period of 20 minutes before being moved to the side of the road. With the incident management system in place, it was assumed that the duration of the incident would be reduced by $50 \%$. Compared to the scenario with no incident management system, traffic flow and fuel efficiency in the integrated arterial/ freeway network was found to improve (refer to Table 4).

Table 4: $\quad$ Effectiveness of incident management.

\begin{tabular}{|l|c|c|}
\hline \multicolumn{1}{|c|}{ Measure of effectiveness } & Base case & $\begin{array}{c}\text { Incident } \\
\text { management }\end{array}$ \\
\hline $\begin{array}{l}\text { Average delay (min/vehicle) } \\
\text { \% change }\end{array}$ & 11.4 & 11.1 \\
\hline Fuel consumption (litres/trip) & - & $-2.6 \%$ \\
$\%$ change & 1.12 & 1.11 \\
\hline
\end{tabular}

Variable message signs are used to provide real-time traffic information to motorists at various locations on the road network. Based on the information provided, motorists can then choose whether or not to deviate from their planned route. In the model, variable message signs were provided on Highway 417 at strategic locations upstream of traffic congestion. To simulate the effects of a 
variable message sign, the model adjusts the traffic assignment assumptions in the vicinity of the sign, allowing motorists to select a new route if a reduction in travel time can be achieved. Since some drivers are less familiar with the road network, they are less inclined to deviate from their original route. To capture this phenomenon, it was assumed that only $80 \%$ of the drivers assigned to a fixed route would reassess their optimal path when passing a variable message sign. The results shown in Table 5 indicate that both average delay and fuel consumption per trip declined with the introduction of this measure.

Table 5: $\quad$ Effectiveness of variable message signs.

\begin{tabular}{|l|c|c|}
\hline \multicolumn{1}{|c|}{ Measure of effectiveness } & Base case & Variable message signs \\
\hline Average delay (min/vehicle) & 10.4 & 10.0 \\
$\%$ change & - & $-3.8 \%$ \\
\hline Fuel consumption (litres/trip) & 1.11 & 1.09 \\
$\%$ change & - & $-1.8 \%$ \\
\hline
\end{tabular}

In the traveller information/navigation scenario, it was assumed that $90 \%$ of drivers receive en-route traveller information describing real-time traffic conditions and that these drivers have in-vehicle navigational systems which continually assess the optimal route to the driver's destination. While this level of technology "uptake" may appear high, such systems are currently under development and are gradually being introduced in cities around the world. If the rate of adoption mirrors that of other in-vehicle technologies such as ABS brakes, such systems could one day become commonplace. The results presented in Table 6 show that of all the ITS measures examined, the traveller information system is one of the most effective. Improvements in delay and fuel consumption compare favourably with the capacity expansion scenario.

Table 6: $\quad$ Effectiveness of traveller information/navigation.

\begin{tabular}{|l|c|c|}
\hline \multicolumn{1}{|c|}{ Measure of effectiveness } & Base case & $\begin{array}{c}\text { Traveller } \\
\text { information/navigatio } \\
n\end{array}$ \\
\hline $\begin{array}{l}\text { Average delay (min/vehicle) } \\
\text { \% change consumption }\end{array}$ & 10.4 & 9.5 \\
\hline Fuel & - & $-8.7 \%$ \\
(litres/trip) & - & 1.06 \\
$\%$ change & & $-4.5 \%$ \\
\hline
\end{tabular}

\section{Conclusions}

A $20 \%$ reduction in vehicle travel leads to both operational and fuel conservation benefits which far exceed those of any of the other scenarios examined. The new capacity scenario also has significant operational and fuel conservation benefits. 
However, over time, induced demand may negate these positive results. Ramp metering shows very favourable results for the freeway facility. However, if the impacts of such a system on the arterial network are included for equity reasons, the results are not likely to be as impressive as shown here. All other ITS-based initiatives have the potential to improve the efficiency of the transportation network and reduce fuel consumption. However, such gains may be short-lived if induced demand materializes. For this reason, a package of measures is needed, some targeted at reducing travel demand, others aimed at improving traffic operations and the efficiency of the transportation network.

Given the microscopic approach employed in the research, the Ottawa case study did not consider the impact of ITS on travel decisions related to the mode or time of travel. Moreover, the study did not consider the potential for operational improvements to trigger induced demand. To fully investigate the implications of adopting new technologies in the transportation sector, there is a need for an integrated modelling framework which incorporates both macroscopic demand models for forecasting travel behaviour, as well as microscopic simulation models for assessing impacts at a traffic operations level of detail.

While simulation models such as CORSIM and INTEGRATION provide valuable insight into the operational impacts of ITS initiatives, such models are only one component of a broader evaluation framework. Cost, safety, and user satisfaction are all key considerations in assessing the relative merit of ITS technologies.

\section{Acknowledgements}

This paper is based on research sponsored by AUTO21, the Ministry of Transportation of Ontario (MTO) and the Natural Sciences and Engineering Research Council of Canada (NSERC). The opinions are those of the authors.

\section{References}

[1] Maccubin, R., Staples, B.L. and Mercer, M.R., Intelligent Transportation Systems Benefits and Costs: 2003 Updates, Report No. FHWA-OP-03075, US Department of Transportation, Washington, D.C., 2003.

[2] Transport Canada, Intelligent Transportation Systems Research and Development Plan for Canada: Innovation through Partnership, Ottawa, 2003, (website: http://www.its-sti.gc.ca/en/randd/menu.htm)

[3] Van Aerde, M. \& Associates Ltd., INTEGRATION Release 2.30 for Windows: User's Guide. Volumes 1 \& 2, Kingston, Ontario, 2003.

[4] Khan, A.M., Fukutomi, A., Taylor, S.J., and Armstrong, J.M., Microsimulation of Traffic for Safety Study of In-Vehicle Intelligent Transportation Systems (Chapter 10). Driver Behaviour and Training. Volume II, ed. Lisa Dorn, Ashgate Publishing: Aldershot, UK, pp.121-132, 2005. 
732 Urban Transport XII: Urban Transport and the Environment in the 21st Century

[5] Alexiadis, V., Colyar, J., Halkias, J., Hranac, R., McHale, G., The Next Generation of Simulation Program. ITE Journal, 74(8): pp. 22-26, 2004.

[6] ITT Industries, Traffic Software Integrated System, Help Manual Version 5.1, Colorado, USA, 2003.

[7] Van Aerde, M. \& Associates Ltd., QUEENSOD Release 2.10 - User's Guide: Estimating Origin-Destination Traffic Demands from Link Flow Counts, Kingston, Ontario, 2002. 